\title{
RELATIVIZATION IN N-ARY TOPOLOGY
}

\section{SEETHALAKSHMI $^{1} \&$ KAMARAJ $^{2}$}

${ }^{I}$ Department of Mathematics, Jaya college of Arts and Science, Thiruninravuir, Tamil Nadu, India

${ }^{2}$ Department of Mathematics, Govt. Arts and Science College, Sivakasi, Tamil Nadu, India

ABSTRACT
Nithyanantha Jothi and Thangavelu introduced the concept of binary topology in 2011. Recently the authors
extended the notion of binary topology to n-ary topology where $n>1$ an integer and studied n-ary closed sets. The purpose
of this paper is to study the n-ary subspaces of a n-ary topological space.
KEYWORDS: Binary Topology, n-ary Topology, n-ary Open, n-ary Closed \& n-ary Subspace
MSC 2010: $54 A 05,54 A 99$

Received: Feb 15, 2019; Accepted: Mar 05, 2019; Published: Mar 23, 2019; Paper Id.: IJMCARJUN20197

\section{INTRODUCTION}

Nithyanantha Jothi and Thangavelu [5-10] introduced the concept of a binary topology and studied the corresponding closure and interior operators in binary topological spaces. Following this topologists studied the notion of binary topology in soft topological, generalized topological and supra topological settings [1-4]. The authors [11] discussed nearly open sets in binary topological spaces and also they extended binary topology to n-ary topology [12] and discussed n-ary closed sets [13]

\section{PRELIMINARIES}

Let $\mathrm{X} 1, \mathrm{X} 2, \mathrm{X} 3, \ldots, \mathrm{Xn}$ be the non empty sets. Then $\mathrm{P}(\mathrm{X} 1) \times \mathrm{P}(\mathrm{X} 2) \times \ldots \times \mathrm{P}(\mathrm{Xn})$ is the Cartesian product of the power sets $\mathrm{P}(\mathrm{X} 1), \mathrm{P}(\mathrm{X} 2), \ldots, \mathrm{P}(\mathrm{Xn})$. Examples can be constructed to show that the two notions 'product of power sets' and 'power set of the products' are different.

Any typical element in $\mathrm{P}(\mathrm{X} 1) \times \mathrm{P}(\mathrm{X} 2) \times \ldots \times \mathrm{P}(\mathrm{Xn})$ is of the form $(\mathrm{A} 1, \mathrm{~A} 2, \ldots, \mathrm{An})$ where $\mathrm{Ai} \subseteq \mathrm{Xi}$ for $\mathrm{i} \in\{1,2,3, \ldots, \mathrm{n}\}$. Suppose $(\mathrm{A} 1, \mathrm{~A} 2, \ldots, \mathrm{An})$ and $(\mathrm{B} 1, \mathrm{~B} 2, \ldots, \mathrm{Bn})$ are any two members in $\mathrm{P}(\mathrm{X} 1) \times \mathrm{P}(\mathrm{X} 2) \times \ldots \times \mathrm{P}(\mathrm{Xn})$. Throughout this paper we use the following notations and terminologies.

$(\mathrm{X} 1, \mathrm{X} 2, \ldots, \mathrm{Xn})$ is an $\mathrm{n}$-ary absolute set and $(\varnothing, \varnothing, \varnothing, \ldots, \varnothing)$ is an $\mathrm{n}$-ary null set or void set or empty set in $\mathrm{P}(\mathrm{X} 1) \times \mathrm{P}(\mathrm{X} 2) \times \ldots \times \mathrm{P}(\mathrm{Xn})$.

$(\mathrm{A} 1, \mathrm{~A} 2, \ldots, \mathrm{An}) \subseteq(\mathrm{B} 1, \mathrm{~B} 2, \ldots, \mathrm{Bn})$ if $\mathrm{Ai} \subseteq \mathrm{Bi}$ for every $\mathrm{i} \in\{1,2,3, \ldots, \mathrm{n}\}$ and

$(\mathrm{A} 1, \mathrm{~A} 2, \ldots, \mathrm{An}) \neq(\mathrm{B} 1, \mathrm{~B} 2, \ldots, \mathrm{Bn})$ if $\mathrm{A} i \neq \mathrm{Bi}$ for some $\mathrm{i} \in\{1,2,3, \ldots, \mathrm{n}\}$.

Equivalently $(A 1, A 2, \ldots, A n)=(B 1, B 2, \ldots, B n)$ if $A i=B i$ for every $i \in\{1,2,3, \ldots, n\}$. If $A i \neq B i$ for each $\mathrm{i} \in\{1,2,3, \ldots, \mathrm{n}\}$ then we say that $(\mathrm{A} 1, \mathrm{~A} 2, \ldots, \mathrm{An})$ is absolutely not equal to $(\mathrm{B} 1, \mathrm{~B} 2, \ldots, \mathrm{Bn})$ which is denoted as $(A 1, A 2, \ldots, A n) a \neq(B 1, B 2, \ldots, B n)$. Let $x i \in X i$ and $A i \subseteq X i$ for every $i \in\{1,2,3, \ldots, n\}$. Then $(x 1, x 2, \ldots, x n) \in(A 1$, 
$\mathrm{A} 2, \ldots, \mathrm{An})$ if $\mathrm{xi} \in \mathrm{Ai}$ for every $\mathrm{i} \in\{1,2,3, \ldots, \mathrm{n}\}$.

\section{Definition 2.1}

Let $\mathrm{Xi}$ be an infinite set for every $\mathrm{i} \in\{1,2,3, \ldots, \mathrm{n}\}$. (A1, A2, ., An) is finite if Ai is finite for every $i \in\{1,2,3, \ldots, \mathrm{n}\}$ and is infinite if $\mathrm{Ai}$ is infinite for some $\mathrm{i} \in\{1,2,3, \ldots, \mathrm{n}\}$.

\section{Definition 2.2}

Let $\mathrm{Xi}$ be an uncountable set for every $\mathrm{i} \in\{1,2,3, \ldots, \mathrm{n}\}$. (A1, A2, .,An) is countable if Ai is countable for every $i \in\{1,2,3, \ldots, n\}$ and is uncountable if $\mathrm{Ai}$ is uncountable for some $i \in\{1,2,3, \ldots, n\}$.

\section{Proposition 2.3}

$(\mathrm{x} 1, \mathrm{x} 2, \ldots, \mathrm{xn}) \in(\mathrm{A} 1, \mathrm{~A} 2, \ldots, \mathrm{An})$ iff $(\mathrm{x} 1, \mathrm{x} 2, \ldots, \mathrm{xn}) \in \mathrm{A} 1 \times \mathrm{A} 2 \times \ldots \times \mathrm{An}$.

The notions of n-ary union, n-ary intersection, n-ary complement and n-ary difference of n-ary sets are defined component wise. Two n-ary sets are said to be n-ary disjoint if the sets in the corresponding positions are disjoint.

Let $\mathrm{X} 1, \mathrm{X} 2, \mathrm{X} 3, \ldots, \mathrm{Xn}$ be the non empty sets. Let $\mathrm{T} \subseteq \mathrm{P}(\mathrm{X} 1) \times \mathrm{P}(\mathrm{X} 2) \times \ldots \times \mathrm{P}(\mathrm{Xn})$.

\section{Definition 2.4}

$\mathrm{T}$ is an $\mathrm{n}$-ary topology on $(\mathrm{X} 1, \mathrm{X} 2, \mathrm{X} 3, \ldots, \mathrm{Xn})$ if the following axioms are satisfied.

- $\quad(\varnothing, \varnothing, \varnothing, \ldots, \varnothing) \in \mathrm{T}$

- $\left(\mathrm{X}_{1}, \mathrm{X}_{2}, \mathrm{X}_{3}, \ldots, \mathrm{X}_{\mathrm{n}}\right) \in \mathrm{T}$

- If $\left(A_{1}, A_{2}, \ldots, A_{n}\right),\left(B_{1}, B_{2}, \ldots, B_{n}\right) \in T$ then

$\left(A_{1}, A_{2}, \ldots, A_{n}\right) \cap\left(B_{1}, B_{2}, \ldots, B_{n}\right) \in T$

- If $\left(\mathrm{A}_{1 \alpha}, \mathrm{A}_{2 \alpha}, \ldots, \mathrm{A}_{\mathrm{n} \alpha}\right) \in \mathrm{T}$ for each $\alpha \in \Omega$ then $\bigcup_{\alpha \in \Omega}\left(\mathrm{A}_{1 \alpha}, \mathrm{A}_{2 \alpha}, \ldots, \mathrm{A}_{\mathrm{n} \alpha}\right) \in \mathrm{T}$.

If $\mathrm{T}$ is an $\mathrm{n}$-ary topology then the pair $(\mathrm{X}, \mathrm{T})$ is called an $\mathrm{n}$-ary topological space where $\mathrm{X}=(\mathrm{X} 1, \mathrm{X} 2, \mathrm{X} 3, \ldots$, $\mathrm{Xn})$. The element $\mathrm{x}=(\mathrm{x} 1, \mathrm{x} 2, \ldots, \mathrm{xn}) \in \mathrm{X}$ is called an $\mathrm{n}$-ary point of $(\mathrm{X}, \mathrm{T})$ and the members $\mathrm{A}=(\mathrm{A} 1, \mathrm{~A} 2, \ldots, \mathrm{An})$ of $\mathrm{P}(\mathrm{X} 1) \times \mathrm{P}(\mathrm{X} 2) \times \ldots \times \mathrm{P}(\mathrm{Xn})$. are called the $\mathrm{n}$-ary sets of $(\mathrm{X}, \mathrm{T})$. The members of $\mathrm{T}$ are called the $n$-ary open sets in $(\mathrm{X}, \mathrm{T})$.

It is noteworthy to see that product topology on $\mathrm{X} 1 \times \mathrm{X} 2 \times \ldots \times \mathrm{Xn}$ and $\mathrm{n}$-ary topology on $(\mathrm{X} 1, \mathrm{X} 2, \mathrm{X} 3, \ldots, \mathrm{Xn})$ are independent concepts as any open set in product topology is a subset of $\mathrm{X} 1 \times \mathrm{X} 2 \times \mathrm{X} 3 \times \ldots \times \mathrm{Xn}$ and an open set in an $\mathrm{n}-\mathrm{ary}$ topology is a member of $\mathrm{P}(\mathrm{X} 1) \times \mathrm{P}(\mathrm{X} 2) \times \ldots \times \mathrm{P}(\mathrm{Xn})$.

\section{Lemma 2.5}

Let $\mathrm{T}$ be an $\mathrm{n}$-ary topology on $(\mathrm{X} 1, \mathrm{X} 2, \ldots, \mathrm{Xn}) . \mathrm{T} 1=\{\mathrm{A} 1:(\mathrm{A} 1, \mathrm{~A} 2, \ldots, \mathrm{A} 2) \in \mathrm{T}\}$ and $\mathrm{T} 2, \mathrm{~T} 3, \ldots, \mathrm{T} \mathrm{n}$ can be similarly defined. Then $\mathrm{T} 1, \mathrm{~T} 2, \ldots, \mathrm{T} \mathrm{n}$ are topologies on $\mathrm{X} 1, \mathrm{X} 2, \ldots, \mathrm{Xn}$ respectively.

\section{Lemma 2.6}

Let $\tau 1, \tau 2, \ldots, \tau \mathrm{n}$ be the topologies on $\mathrm{X} 1, \mathrm{X} 2, \ldots, \mathrm{Xn}$ respectively. 
Let $\mathrm{T}=\tau 1 \times \tau 2 \times \ldots \times \tau \mathrm{n}=\{(\mathrm{A} 1, \mathrm{~A} 2, \ldots, \mathrm{A} 2): \mathrm{Ai} \in \tau \mathrm{i}\}$. Then $\mathrm{T}$ is an $\mathrm{n}$-ary topology on $\mathrm{X}=(\mathrm{X} 1, \mathrm{X} 2, \ldots, \mathrm{Xn})$. Moreover $\mathrm{T} i=\tau \mathrm{i}$ for every $\mathrm{i} \in\{1,2,3, \ldots, \mathrm{n}\}$.

\section{Definition 2.7}

Let $(\mathrm{A} 1, \mathrm{~A} 2, \ldots, \mathrm{An})$ be an element of $\mathrm{P}(\mathrm{X} 1) \times \mathrm{P}(\mathrm{X} 2) \times \ldots \times \mathrm{P}(\mathrm{Xn})$. Then $(\mathrm{A} 1, \mathrm{~A} 2, \ldots, \mathrm{An})$ is $n$-ary closed in $(\mathrm{X} 1, \mathrm{X} 2$, $\mathrm{X} 3, \ldots, \mathrm{Xn} ; \mathrm{T})$ if $(\mathrm{A} 1, \mathrm{~A} 2, \ldots, \mathrm{An}) \mathrm{c}=(\mathrm{X} \backslash \mathrm{A} 1, \mathrm{X} \backslash \mathrm{A} 2, \ldots, \mathrm{X} \backslash \mathrm{An})$ is n-ary open in $(\mathrm{X}, \mathrm{T})$.

\section{THE N-ARY BASIS AND N-ARY SUB BASIS}

Let $\mathrm{X} 1, \mathrm{X} 2, \mathrm{X} 3, \ldots, \mathrm{Xn}$ be the non empty sets. Let $\mathrm{T} \subseteq \mathrm{P}(\mathrm{X} 1) \times \mathrm{P}(\mathrm{X} 2) \times \ldots \times \mathrm{P}(\mathrm{Xn})$ be an $\mathrm{n}$-ary topology on $(\mathrm{X} 1, \mathrm{X} 2$, $\mathrm{X} 3, \ldots, \mathrm{Xn})$.

\section{Definition 3.1}

A sub collection $\mathrm{B}$ of $\mathrm{T}$ is called an $\mathrm{n}$-ary basis for (X, T ) if every member of $\mathrm{T}$ is an $\mathrm{n}$-ary union of members of $\mathrm{B}$ and a sub collection $\mathrm{S}$ of $\mathrm{T}$ is a sub basis for $(X, T)$ if the $n$-ary intersections of finitely many members of $\mathrm{S}$ form an $\mathrm{n}$ ary basis for $(\mathrm{X}, \mathrm{T})$.

\section{Proposition 3.2}

A collection $B$ of $n$-ary elements of $\mathrm{P}(\mathrm{X} 1) \times \mathrm{P}(\mathrm{X} 2) \times \ldots \times \mathrm{P}(\mathrm{Xn})$ is an $n$-ary basis for some $\mathrm{n}$-ary topology

$\mathrm{T}(\mathrm{B})$ on $\mathrm{X}$ if and only if

- the n-ary union of all members of $B$ is $\left(X_{1}, X_{2}, \ldots, X_{n}\right)$ and

- $\mathrm{T}(\mathrm{B})=\left\{\mathrm{G} \in \mathrm{P}\left(\mathrm{X}_{1}\right) \times \mathrm{P}\left(\mathrm{X}_{2}\right) \times \ldots \times \mathrm{P}\left(\mathrm{X}_{\mathrm{n}}\right)\right.$ : for every $\mathrm{x} \in \mathrm{G}$ there exists a $\mathrm{B} \in \mathrm{B}$ with $\left.\mathrm{x} \in \mathrm{B} \subseteq \mathrm{G}\right\}$.

\section{Remark 3.3}

$\mathrm{T}(\mathrm{B})$ is called the n-ary topology generated by B as an n-ary basis.

\section{Proposition 3.4}

A collection $S$ of n-ary elements of $\mathrm{P}(\mathrm{X} 1) \times \mathrm{P}(\mathrm{X} 2) \times \ldots \times \mathrm{P}(\mathrm{Xn})$ is an $n$-ary

Sub basis for some n-ary topology $\mathrm{T}(\mathrm{S})$ on $\mathrm{X}$ iff

- the n-ary union of all members of $B$ is $(X 1, X 2, \ldots, X n)$ and

- $\mathrm{T}(\mathrm{S})=\{\mathrm{G} \in \mathrm{P}(\mathrm{X} 1) \times \mathrm{P}(\mathrm{X} 2) \times \ldots \times \mathrm{P}(\mathrm{Xn})$ : for every $\mathrm{x} \in \mathrm{G}$ there exists $\mathrm{B}$ and $\mathrm{C}$ in $\mathrm{S}$ with $\mathrm{x} \in \mathrm{B} \cap \mathrm{C} \subseteq \mathrm{G}\}$.

\section{Remark 3.5}

$\mathrm{T}(\mathrm{S})$ is called the n-ary topology generated by $\mathrm{S}$ as an n-ary sub basis.

\section{Remark 3.6}

An n-ary basis or n-ary sub basis of an n-ary topology $\mathrm{T}$ completely determines the $\mathrm{n}$-ary topology $\mathrm{T}$.

\section{Proposition 3.7}

A collection $B$ of $n$-ary elements of $\mathrm{P}(\mathrm{X} 1) \times \mathrm{P}(\mathrm{X} 2) \times \ldots \times \mathrm{P}(\mathrm{Xn})$ is an $n$-ary basis for the n-ary topology $\mathrm{T}(\mathrm{B})$ on $\mathrm{X}$ 
iff

- for every $\mathrm{x} \in \mathrm{X}$ there exists $\mathrm{B} \in \mathrm{B}$ with $\mathrm{x} \in \mathrm{B} \subseteq \mathrm{X}$ and

- for every $\mathrm{x} \in \mathrm{X}$ and for any two members $\mathrm{C}$ and $\mathrm{D}$ of $\mathrm{B}$ with $\mathrm{x} \in \mathrm{C} \cap \mathrm{D}$ there exists $\mathrm{B} \in \mathrm{B}$ with $\mathrm{x} \in \mathrm{B} \subseteq \mathrm{C} \cap \mathrm{D}$.

\section{Remark 3.8}

If B satisfies (i) and (ii) of Proposition 3.7. then T (B) consists of $(\varnothing, \varnothing, \varnothing, \ldots, \varnothing),(\mathrm{X} 1, \mathrm{X} 2, \mathrm{X} 3, \ldots, \mathrm{Xn})$ and all nary unions of members of $\mathrm{B}$.

\section{Proposition 3.9}

Suppose $\mathrm{B}$ and $\mathrm{B}^{\prime}$ generate the $\mathrm{n}$-ary topologies $\mathrm{T}(\mathrm{B})$ and $\mathrm{T}\left(\mathrm{B}^{\prime}\right)$ Respectively on $\mathrm{X}$ as n-ary bases. Then $\mathrm{T}\left(\mathrm{B}^{\prime}\right)$ is finer than $T(\mathrm{~B})$ iff for every $\mathrm{x} \in \mathrm{X}$ and for every $\mathrm{B} \in \mathrm{B}$ there exists $\mathrm{B}^{\prime} \in \mathrm{B}^{\prime}$ with $\mathrm{x} \in \mathrm{B}^{\prime} \subseteq \mathrm{B}$.

\section{Proposition 3.10}

Suppose $B$ and $\mathrm{B}^{\prime}$ generate the $\mathrm{n}$-ary topologies $\mathrm{T}(\mathrm{B})$ and $T\left(\mathrm{~B}^{\prime}\right)$ Respectively on $\mathrm{X}$ as $\mathrm{n}$-ary bases. Then $\mathrm{T}\left(\mathrm{B}^{\prime}\right)=$ $\mathrm{T}(\mathrm{B})$ iff

- for every $\mathrm{x} \in \mathrm{X}$ and for every $\mathrm{B} \in \mathrm{B}$ there exists $\mathrm{B}^{\prime} \in \mathrm{B}^{\prime}$ with $\mathrm{x} \in \mathrm{B}^{\prime} \subseteq \mathbf{B}$

- for every $\mathrm{x} \in \mathrm{X}$ and for every $\mathrm{B}^{\prime} \in \mathrm{B}^{\prime}$ there exists $\mathrm{B} \in \mathrm{B}$ with $\mathrm{x} \in \mathrm{B} \subseteq \mathbf{B}^{\prime}$.

\section{N-ARY SUBSPACE}

Let $X=\left(X_{1}, X_{2}, \ldots, X_{n}\right)$ and $Y=\left(Y_{1}, Y_{2}, \ldots, Y_{n}\right)$ such that $Y \subseteq X$.

\section{Definition 4.1}

Let $\mathrm{T}$ be an $\mathrm{n}$-ary topology on $\mathrm{X}$. Then $\mathrm{T} \mathrm{Y}=\{\mathrm{Y} \cap \mathrm{A}: \mathrm{A}=(\mathrm{A} 1, \mathrm{~A} 2, \ldots, \mathrm{A} 2) \in \mathrm{T}\}$.

\section{Proposition 4.2}

$\mathrm{T} \mathrm{Y}$ is an n-ary topology on $\mathrm{Y}$.

\section{Proof}

If $\mathrm{A}=(\mathrm{A} 1, \mathrm{~A} 2, \ldots, \mathrm{A} 2)$ then $\mathrm{Y} \cap \mathrm{A}=(\mathrm{Y} 1, \mathrm{Y} 2, \ldots, \mathrm{Yn}) \cap(\mathrm{A} 1, \mathrm{~A} 2, \ldots, \mathrm{A} 2)=(\mathrm{Y} 1 \cap \mathrm{A} 1, \mathrm{Y} 2 \cap \mathrm{A} 2, \ldots, \mathrm{Yn} \cap \mathrm{An})$ is an $\mathrm{n}-$ ary element of $\mathrm{P}(\mathrm{Y} 1) \times \mathrm{P}(\mathrm{Y} 2) \times \ldots \times \mathrm{P}(\mathrm{Yn})$. which in turn is an nary element of $\mathrm{P}(\mathrm{X} 1) \times \mathrm{P}(\mathrm{X} 2) \times \ldots \times \mathrm{P}(\mathrm{Xn})$. Therefore it is easy to show that $\mathrm{T} \mathrm{Y}$ is an $\mathrm{n}$-ary topology on $\mathrm{Y}$.

\section{Definition 4.3}

The $\mathrm{n}$-ary topology $\mathrm{T} \mathrm{Y}$ on $\mathrm{Y}$ is inherited from $\mathrm{T}$ or induced by $\mathrm{T}$. The pair $(\mathrm{Y}, \mathrm{T} \mathrm{Y})$ is called the $\mathrm{n}$-ary subspace of $(X, T)$.

The next six propositions can be easily proved.

\section{Proposition 4.4}

If $\mathrm{B}$ is an $\mathrm{n}$-ary basis for $\mathrm{T}$ then $\{\mathrm{Y} \cap \mathrm{B}: \mathrm{B} \in \mathrm{B}\}$ is an $\mathrm{n}$-ary basis for $\mathrm{T} \mathrm{Y}$. 


\section{Proposition 4.5}

If $\mathrm{S}$ is an $\mathrm{n}$-ary sub basis for $\mathrm{T}$, then $\{\mathrm{Y} \cap \mathrm{B}: \mathrm{B} \in \mathrm{S}\}$ is an $\mathrm{n}$-ary sub basis for $\mathrm{T} \mathrm{Y}$

\section{Proposition 4.6}

Let $\mathrm{A} \subseteq \mathrm{Y} \subseteq \mathrm{X}$. Then $\mathrm{A}$ is $\mathrm{n}$-ary closed in $(\mathrm{Y}, \mathrm{T} \mathrm{Y})$ iff $\mathrm{A}=\mathrm{Y} \cap \mathrm{F}$ for some $\mathrm{n}$-ary closed set $\mathrm{F}$ in $(\mathrm{X}, \mathrm{T})$.

\section{Proposition 4.7}

Let $\mathrm{A} \subseteq \mathrm{Y} \subseteq \mathrm{X}$. Then

- $\quad(\mathrm{n}-C l \mathrm{~A})_{\mathrm{Y}}=\mathrm{Y} \cap(\mathrm{n}-C l \mathrm{~A})$

- $\mathrm{Y} \cap(\mathrm{n}-\operatorname{Int} \mathrm{A}) \subseteq \mathrm{n}-\operatorname{Int} \mathrm{A}$.

\section{Proposition 4.8}

Let $\mathrm{A} \subseteq \mathrm{Y} \subseteq \mathrm{X}$. Then

- If $\mathrm{Y}$ is $\mathrm{n}$-ary closed in $(\mathrm{X}, \mathrm{T})$ then $\mathrm{A}$ is $\mathrm{n}$-ary closed in $(\mathrm{Y}, \mathrm{T} \mathrm{Y}) \Leftrightarrow \mathrm{A}$ is $\mathrm{n}$-ary closed in $(\mathrm{X}, \mathrm{T})$.

- If $\mathrm{Y}$ is $\mathrm{n}$-ary open in $(\mathrm{X}, \mathrm{T})$ then $\mathrm{A}$ is $\mathrm{n}$-ary open in $(\mathrm{Y}, \mathrm{T} \mathrm{Y}) \Leftrightarrow \mathrm{A}$ is $\mathrm{n}$-ary open in $(\mathrm{X}, \mathrm{T})$.

\section{Proposition 4.9}

Let $\mathrm{Z} \subseteq \mathrm{Y} \subseteq \mathrm{X}$. Then $(\mathrm{T} \mathrm{Y}) \mathrm{Z}=\mathrm{T} \mathrm{Z}$.

\section{CONCLUSIONS}

The notions of n-ary basis and n-ary sub basis are discussed in n-ary topological spaces. Further the n-ary subspaces of an n-ary space are characterized by using these notions.

\section{REFERENCES}

1. Arif Mehmood khattak et, d., Soft subspaces and soft b-separation axiom in Binary Soft topological spaces, Journal of New Theory 23(2018), 48-62.

2. S. S. Benchalli, P. G. Patil, S. Abeda Dodamani and J. Pradeepkumar, "On Binary Soft Separation Axioms in Binary Soft Topological Spaces”, Global Journal of Pure and Applied Mathematics, vol.13, no.9, pp. 5393-5412, 2017.

3. M. Jamal Mustafa, "On Binary Generalized Topological Spaces", General Letters in Mathematics, vol.2, no.3, pp.111-116, 2017.

4. M. Lellish Thivagar, J. Kavitha, "On Binary Structure of Supra topological spaces", Bol. Soc. Paran. Mat., vol.35, no.3, pp.25-37, 2017.

5. S. Nithyanantha Jothi, "Binary semicontinuous functions", International Journal of Mathematics Trends and Technology, vol.49, no.2, pp.152-155, 2017.

6. S. Nithyanantha Jothi, P. Thangavelu, "Topology Between Two Sets", Journal of Mathematical Sciences and Computer Applications, vol.1, no.3, pp.95-107, 2011.

7. S. Nithyanantha Jothi, P. Thangavelu, "On Binary Topological Spaces", Pacific-Asian Journal Mathematics, vol.5, no.2, pp.133-138, 2011. 
8. Okoronka, A. U., \& Taale, K. D. Analogies, Problem-Solving and Concept Mapping Instructional Strategies as Determinants of Senior Secondary School Students'achievement in Wave Concepts in Adamawa State, Nigeria.

9. S. Nithyanantha Jothi, P. Thangavelu, "Generalized Binary Regular Closed Sets", IRA International Journal of Applied Sciences, vol.4, no.2, pp.259-263, 2011.

10. S. Nithyanantha Jothi, P. Thangavelu, "On Binary Continuity and Binary Separation Axioms", Ultra Scientists vol.24, no.1A, pp.121-126, 2012

11. S. Nithyanantha Jothi, P. Thangavelu, "Binary semiopen sets in Binary Topological Spaces", International Journal of Mathematical Archiv, vol.7, no.9, pp.73-76, 2016.

12. R. Seethalakshmi, K. Kamaraj, "Nearly Binary Open Sets in Binary Topological Spaces”, International Conference On Applied and Computational Mathematics(ICACM- 2018), Erode Arts and Science College(Autonomous) Rangampalaym, Erode-638009, Tamilnadu, India, 2018.

13. R. Seethalakshmi, K. Kamaraj, Combinatorial properties and n-ary topology on product of power sets, International Journal of New Innovations in Engineering and Technology, 9(3)(2018), 018-022.

14. Maheswari, A. (2014). Imaginary Roots And Dynkin Diagrams Of Quasi Hyperbolic Kac Moody Algebras Of Rank 3.

15. R. Seethalakshmi, K. Kamaraj, n-ary closed sets, International Conference on Mathematical Modelling Analysis Computing(MMAC-18), Thiruvalluvar University, Vellore, India, Dec.3-14, 2018. 